\title{
Mehran risk score model for predicting contrast-induced nephropathy after cardiac resynchronization therapy in patients with heart failure
}

\author{
(1) Mehmet Akif Erdol'1, (1) Ahmet Ertem¹, (1) Ali Can Özkan'1, (1) Mustafa Özbay², (1) Mehmet Erdoğan³, \\ (1) Koray Demirtaş ${ }^{1}$, (1) Mustafa Karanfil ${ }^{1}$, (1) Ahmet Akdi ${ }^{1}$, (1) Çağrı Yayla ${ }^{1}$, (1) Adnan Burak Akçay ${ }^{1}$, \\ (1) Serkan Topaloğlu'
}

1 University of Health Sciences Turkey, Ankara City Hospital, Clinic of Cardiology, Ankara, Turkey

2Ankara Halil Sivgin Cubuk State Hospital, Clinic of Cardiology, Ankara, Turkey

${ }^{3}$ Ankara Yildirim Beyazit University, Ankara City Hospital, Clinic of Cardiology, Ankara, Turkey

\section{Date submitted:}

21.10.2021

Date accepted:

15.11.2021

Online publication date:

15.03.2022

\section{Corresponding Author:}

Mehmet Akif Erdol, M.D., University of Health Sciences Turkey, Ankara City

Hospital, Clinic of Cardiology, Ankara, Turkey

akiferdol@gmail.com

ORCID:

orcid.org/0000-0002-2721-440X

Keywords: Cardiac resynchronization therapy, contrast-induced

nephropathy, Mehran risk score, heart failure

\begin{abstract}
Aims: Contrast-induced nephropathy $(\mathrm{CIN})$ is a challenging condition after cardiac procedures. Mehran risk score (MS) is a simple tool for predicting CIN. We investigated the role of MS to predict CIN development following cardiac resynchronization therapy (CRT) implantation in heart failure (HF) patients.
\end{abstract}

Methods: This single-center, retrospective study included HF patients who underwent CRT implantation. The patients had New York Heart Association class II-IV disease, wide QRS in electrocardiogram (>130 ms), and diminished left ventricular ejection fraction $(<35 \%)$. Patients with active bleeding, acute renal failure before the CRT procedure, liver cirrhosis, autoimmune disease, chronic or acute inflammatory diseases, end-stage malignancy, and receiving dialysis were excluded. Mehran CIN risk score was calculated using the patient records.

Results: The study included 144 patients (age, mean \pm standard deviation: $63 \pm 10$, male sex: 75\%). Patients who developed CIN had significantly higher MS than those who did not $(10.4 \pm 3.3$ vs. 7.6 $\pm 2.7, \mathrm{p}<0.001)$. Multivariate logistic regression analyses showed that contrast volume [Odds ratio (OR): 1.02, 95\% confidence interval $(\mathrm{Cl}): 1.00-1.04, \mathrm{p}=0.029$ ] and MS (OR: $1.3495 \%$ $\mathrm{Cl}$ : $1.10-1.63, \mathrm{p}=0.004$, respectively) were independently associated with development of CIN.

Conclusions: This study showed that higher MS was independently associated with CIN in HF patients who underwent CRT implantation.

\section{Introduction}

Heart failure (HF) is the most prevalent reason for morbidity and mortality worldwide. Management of HF consists of pharmacotherapy and device-based therapy (1). Cardiac resynchronization therapy (CRT) has been developed as a potent treatment for advanced HF patients with prolonged QRS duration greater than or equal to $130 \mathrm{~ms}$ despite optimal pharmacotherapy (2). CRT improves mechanical synchrony by pacing both the LV free wall and septal. The CRT improves left ventricular (LV) ejection fraction (LVEF), survival, 6-min-walk distance, and QRS duration (3). Due to the progressive increase in the incidence of HF population and broadened indications for CRT, it is being performed more frequently worldwide (4).

A detailed coronary sinus (CS) anatomy evaluation via coronary venous angiography, which is the gold standard, is essential to ensure optimal placement of the LV lead (5). 
Nevertheless, this procedure necessitates contrast material administration to identify and cannulate the CS. The most common reason for failure in CRT devices is the failure to cannulate CS ostium (6). However, the contrast administration in this set of patient populations brings the risk of contrast-induced nephropathy (CIN). Major risk factors for the progression of CIN involve congestive HF, pre-existing reduced kidney function, older age, diabetes mellitus (DM), and contrast material load (7-9). CIN has been revealed to be more common than the most recognized complications of CRT implantation (10).

Besides, the development of CIN following CRT has an important negative impact on morbidity and long-term prognosis (11). Therefore, it is essential to determine risk factors for CIN to take preventive precautions. Mehran et al. (12) developed a risk score in 2004 to predict the risk of CIN after percutaneous coronary interventions ( $\mathrm{PCl})$. The Mehran risk score (MS) is the most widely accepted and simple to calculate tool for estimating CIN. Several risk factors have been described for CIN MS based on hypotension, use of an intra-aortic balloon, congestive HF, advanced age, anemia, DM, contrast material volume, and glomerular filtration rate (GFR). It is categorized into 4 groups according to the scores obtained from these parameters. This single-center study aimed to assess the prediction of MS on the CIN of chronic HF patients with CRT.

\section{Methods}

This single-center, retrospective study included medically refractory $\mathrm{HF}$ patients who underwent CRT implantation between February 2019 and February 2021. The inclusion criteria were New York Heart Association (NYHA) class II-IV disease, wide QRS in electrocardiogram (ECG) (>130 ms), and diminished LVEF (<35\%) (13). Patients with active bleeding, acute renal failure before CRT procedure, liver cirrhosis, autoimmune disease, chronic or acute inflammatory diseases, end-stage malignancy, and receiving dialysis were excluded. Additionally, subjects on angiotensin receptor-neprilysin inhibitor (ARNI), renin-angiotensin-aldosterone system blockers, mineralocorticoid receptor antagonists (MRA), diuretics, and digoxin 24-48 hours before the procedure were excluded from the study.

The successful CRT implantation was defined as implantation of LV lead into the appropriate branch of the CS, a right ventricular lead in the optimal position, and a right atrial lead if needed.

Clinical assessment included the evaluation of the NYHA functional class. All patients' 2-dimensional and Doppler echocardiographic examinations were recorded to calculate EF in terms of suitability for CRT. A 2-4 MHz transducer (Philips Affiniti 50, Philips Healthcare, Andover, Netherlands) is used for echocardiographic examinations in our clinic (14). White blood cell count, platelet count, creatinine, and hemoglobin level were obtained from the patient records.

CIN was defined as an increase in creatinine concentration $0.5 \mathrm{mg} / \mathrm{dL}$ ( $44 \mathrm{~mol} / \mathrm{L}$ ), or $25 \%$ above baseline, within $48 \mathrm{~h}$ of contrast administration (12). Patients were divided into two groups according to the development of CIN.

MS was calculated for all patients, which Mehran et al. (12) defined. It is calculated by summing the scores from the following findings: hypotension ( 5 points, if systolic blood pressure $<80$ $\mathrm{mmHg}$ for at least 1 hour requiring inotropic support), use of intra-aortic balloon pump (5 points), congestive HF (5 points, if class III/IV by NYHA classification or history of pulmonary edema), age ( 4 points, if $>75$ years), anemia ( 3 points, if hematocrit $<39 \%$ for men and $<36 \%$ for women), DM (3 points), contrast media volume (1 point per $100 \mathrm{~mL}$ ), and estimated GFR (GFR; in $\mathrm{mL} / \mathrm{min}$ per $1.73 \mathrm{~m}^{2} ; 2$ points, if GFR 60 to $40 ; 4$ points, if GFR 40 to $20 ; 6$ points, if GFR <20). It is categorized into 4 groups: low risk, <6 points; moderate risk, 6-10 points; high risk, $11-15$ points; and very high risk, $>15$ points). Contrast material volume was estimated using the amount for visualization of the CS.

The study was approved by the Ankara City Hospital Institutional Ethics Committee (decision no: E2-20-57, date: 16.12.2020).

\section{Statistical Analysis}

IBM Statistical Package for the Social Sciences Statistics for Macintosh, version 24.0 (IBM Corp., Armonk, New York, USA) was used to perform the statistical calculations. The results were displayed as mean \pm standard deviation (SD), median (interquartile range), and number (percentage), where appropriate. Kolmogorov-Smirnov test was used to test the normality of distribution. Student's t-test and Mann-Whitney $U$ were used for the comparison of continuous variables according to the normality. The chi-square test was used to compare the categorical variables. Logistic regression analysis was performed to explore the variables that were independently associated with a CIN diagnosis. Potential confounding factors for developing $\mathrm{CIN}$ were tested in univariate analysis, including age, gender, DM, hypertension, coronary artery disease, dyslipidemia, ischemic HF, treatment with an MRA, or renin-angiotensin-aldosterone system blocker, contrast material volume, baseline creatinine level, LVEF, and MS. The variables that showed a crude association with a $p<0.100$ in univariate analysis were entered in the multivariate model. The goodness-of-fit assumption was examined by the HosmerLemeshow method and satisfied when the p-value was above 0.05. Receiver operating characteristic (ROC) curve analyses 
were performed to define the cut-off values for the sensitivity and specificity of MS and contrast material volume to predict the diagnosis of CIN. The area under the ROC curve (AUC) was assessed with a $95 \%$ confidence interval $(\mathrm{Cl})$ in addition to specificity and sensitivity. A two-sided p-value of less than 0.05 was defined to be statistically significant.

\section{Results}

\section{Basic characteristics}

The study included 144 patients (age, mean \pm SD: $63 \pm 10$, male sex: $75 \%$ ). Table 1 shows the demographic, clinical, laboratory, and treatment characteristics of the study population. Compared with CIN (-) patients, CIN (+) patients were significantly older, had higher mean creatinine levels, and lower lymphocyte count and platelet count $(p=0.010, p=0.019, p=0.007$, and $p=0.031$, respectively). There was no statistically significant difference in the frequency of smoking, DM, hypertension, dyslipidemia, chronic obstructive pulmonary disease, anemia, coronary artery disease, cerebrovascular disease, ischemic HF, peripheral artery disease, treatments, and other laboratory variables in patients with and without CIN.

In the whole group, ECG revealed a left bundle branch block in one hundred thirty-nine patients (Table 2). The remaining had the right bundle branch block. Patients with CIN had a longer length of hospital stay and received higher contrast material volume ( $p=0.001$, and $p<0.001$, respectively). Patients with $\mathrm{CIN}$ had lower EF than CIN (-) patients ( $22 \pm 6 \%$ vs. $26 \pm 7 \%, p=0.005$ ), and higher NYHA class III-IV (38\% vs. $18 \%, p=0.023)$ (Table 2$)$.

\section{Mehran score evaluation}

As demonstrated in Table 3, univariate logistic regression analyses showed that age [Odds ratio (OR): $1.06,95 \% \mathrm{Cl}$ : 1.01-1.11, $\mathrm{p}=0.021$ ], contrast volume (OR: $1.03,95 \% \mathrm{Cl}: 1.02-$ 1.05, $p<0.001$ ), creatinine level (OR: $2.85,95 \% \mathrm{Cl}: 1.12-7.22$, $\mathrm{p}=0.027$ ), LVEF (OR: 0.92, 95\% Cl: 0.86-0.98, $\mathrm{p}=0.008$ ), and MS (OR: $1.35,95 \% \mathrm{Cl}: 1.17-1.56, \mathrm{p}<0.001$ ) showed association with the development of $\mathrm{CIN}$. Multivariable logistic regression analyses showed contrast volume (OR: $1.02,95 \% \mathrm{Cl}: 1.00-$ 1.04, $\mathrm{p}=0.029)$ and MS (OR: 1.34, 95\% Cl: 1.10-1.63, $\mathrm{p}=0.004)$ independently associated with the development of $\mathrm{CIN}$.

\section{Sensitivity and specificity analysis}

On admission, MS of 8.5 showed a sensitivity of $69 \%$ and specificity of $71 \%$ (AUC: $0.743,95 \% \mathrm{Cl}: 0.645-0.841, \mathrm{p}<0.001$ ) for the prediction of CIN in this study population (Table 4). The cut-off for the contrast material volume for predicting $\mathrm{CIN}$ was 43 $\mathrm{mL}$, with a sensitivity of $65 \%$ and specificity of $80 \%$ (AUC: 0.819 , 95\% Cl: 0.751-0.886, p<0.001) (Figure 1, Table 4).

\section{Discussion}

This study showed that MS can be used as a predictor of CIN in patients undergoing CRT implantation, with a cut-off value of 8.5 and more than $65 \%$ sensitivity and specificity. This is the first study demonstrating that MS is an independent CIN predictor among patients undergoing CRT implantation.

CRT implantation complicated with $\mathrm{CIN}$ has higher mortality and morbidity than those without CIN (11). Therefore, determining the factors that may cause $\mathrm{CIN}$ in the preoperative period will help identify the patients in the risky group.

CIN is one of the most important complications of percutaneous cardiovascular procedures with an important effect on the long-term prognosis in this set of patients $(11,15,16)$. Several potential pathophysiological pathways that can cause CIN have been reported. However, the pathogenesis of kidney damage is still not precisely elucidated. Nonetheless, iodinated contrast causes direct cellular damage to renal tubular cells leading to swelling, blebbing, and apoptosis in tubular cells (17). Additionally, microembolism due to catheter manipulation, which is not easily identifiable clinically may, at least in part, lead to $\mathrm{CIN}(18)$.

Although $\mathrm{PCl}$ and coronary angiography are the most common causes for developing $\mathrm{CIN}$, the incidence of $\mathrm{CIN}$ after CRT implantation is similar to that of coronary procedures. $\mathrm{CIN}$ is a serious and frequent procedural complication of CRT implantation with a significant negative influence on longterm survival. Generally, less contrast volume is used in CRT implantation than $\mathrm{PCl}$. Besides, patients with chronic HF have more comorbid chronic kidney disease. Therefore, although less contrast is required in the CRT procedure, the risk of developing $\mathrm{CIN}$ is increased (11).

CIN incidence was $20.1 \%$ in our study. This number is higher than the findings published by other authors despite the use of less amount of contrast medium $(10,11,19)$. Our study sample received a mean contrast volume of $36 \mathrm{~mL}$. In other studies, however, more than $100 \mathrm{~mL}$ contrast volume was used $(10,11,19)$. Nonetheless, our study repeatedly confirmed that $\mathrm{CIN}$ is the most common procedural complication in patients undergoing CRT implantation. Less contrast usage was not associated with failed LV lead implantation. The decrease in failed LV lead implantation is associated with increased operator experience (19). Thus, CRT implantation by experienced operators is an essential preventive strategy in patients with high-risk factors.

HF and lower EF are among the most significant risk factors for CIN development in patients receiving CRT implantation $(10,12)$. In our study, patients with CIN had lower EF compared to patients without CIN. However, lower EF was not found as an independent risk factor for the development of $\mathrm{CIN}$. This finding may be related to the small number of patients in the study. 


\begin{tabular}{|c|c|c|c|c|}
\hline & Total $(n=144)$ & $\operatorname{CIN}(+)(n=29)$ & $\operatorname{CIN}(-)(n=115)$ & $p$ \\
\hline \multicolumn{5}{|l|}{ Demographic and clinical features } \\
\hline Age, years, mean $\pm S D$ & $63 \pm 10$ & $67 \pm 9$ & $62 \pm 10$ & 0.010 \\
\hline \multicolumn{5}{|l|}{ Gender, $n(\%)$} \\
\hline Male & $108(75)$ & $19(65)$ & $89(77)$ & \multirow{2}{*}{0.187} \\
\hline Female & $36(25)$ & $10(35)$ & $26(23)$ & \\
\hline Diabetes mellitus, $\mathrm{n}(\%)$ & $66(46)$ & $17(59)$ & $49(43)$ & 0.122 \\
\hline Hypertension, n (\%) & $97(67)$ & $17(59)$ & $80(70)$ & 0.261 \\
\hline Coronary artery disease, $\mathrm{n}(\%)$ & $85(59)$ & $20(69)$ & $65(56)$ & 0.223 \\
\hline Dyslipidemia, n (\%) & $74(51)$ & $16(55)$ & $58(50)$ & 0.648 \\
\hline COPD, n (\%) & $20(14)$ & $7(24)$ & $13(11)$ & 0.078 \\
\hline Peripheral artery disease, $\mathrm{n}(\%)$ & $4(3)$ & $2(7)$ & $2(2)$ & 0.131 \\
\hline Cerebrovascular disease, $\mathrm{n}(\%)$ & $15(10)$ & $3(10)$ & $12(10)$ & 0.989 \\
\hline Smoker, n (\%) & $59(41)$ & $12(41)$ & $47(42)$ & 0.983 \\
\hline Ischemic heart failure, $\mathrm{n}(\%)$ & $82(57)$ & $19(66)$ & $63(55)$ & 0.297 \\
\hline Anemia, n (\%) & $27(19)$ & $10(34)$ & $17(15)$ & 0.116 \\
\hline \multicolumn{5}{|l|}{ Treatments } \\
\hline Beta-blockers, n (\%) & $142(99)$ & $29(100)$ & $113(99)$ & 0.475 \\
\hline ARNI, n (\%) & $6(4)$ & $0(0)$ & $6(5)$ & 0.209 \\
\hline MRA, n (\%) & $110(76)$ & $21(72)$ & $89(77)$ & 0.573 \\
\hline Non-dihydropyridine CCBs, $\mathrm{n}(\%)$ & $11(8)$ & $4(14)$ & $7(7)$ & 0.163 \\
\hline Dihydropyridine CCBs, n (\%) & $144(100)$ & $29(100)$ & $115(100)$ & - \\
\hline RAAS blockers, $\mathrm{n}(\%)$ & $126(87)$ & $25(86)$ & $101(88)$ & 0.814 \\
\hline Furosemide, $\mathrm{n}(\%)$ & $112(78)$ & $25(86)$ & $87(76)$ & 0.222 \\
\hline Thiazide, n (\%) & $29(20)$ & $5(17)$ & $24(21)$ & 0.663 \\
\hline Ivabradine, n (\%) & $13(9)$ & $1(3)$ & $12(10)$ & 0.241 \\
\hline Statins, $\mathrm{n}(\%)$ & $56(39)$ & $9(31)$ & $47(41)$ & 0.332 \\
\hline Digoxin, n (\%) & $6(4)$ & $2(7)$ & $4(4)$ & 0.410 \\
\hline \multicolumn{5}{|l|}{ Laboratory parameters } \\
\hline WBC, K/uL $\times 10^{3}$, median $\left(25^{\text {th }}-75^{\text {th }} I Q R\right)$ & $7.6(6.5-9.1)$ & $7.6(5.8-8.8)$ & $7.55(6.6-9.1)$ & 0.221 \\
\hline Neutrophil, K/uL $\times 10^{3}$, mean \pm SD & $5.1 \pm 1.8$ & $5.1 \pm 2.1$ & $5.0 \pm 1.7$ & 0.786 \\
\hline Lymphocyte, K/uL, $x 10^{3}$, median $\left(25^{\text {th }}-75^{\text {th }}\right.$ IQR $)$ & $1.9(1.3-2.3)$ & $1.5(12 .-1.9)$ & $2.1(1.4-2.3)$ & 0.007 \\
\hline Platelets, K/uL, $\times 10^{3}$, median $\left(25^{\text {th }}-75^{\text {th }}\right.$ IQR $)$ & $233(195-281)$ & $215(178-244)$ & $239(202-287)$ & 0.031 \\
\hline Hemoglobin, g/dL, mean $\pm S D$ & $13.4 \pm 1.67$ & $12.8 \pm 1.92$ & $13.5 \pm 1.57$ & 0.066 \\
\hline Hematocrit, mean $\pm S D$ & $40.5 \pm 4.9$ & $39.0 \pm 5.6$ & $40.9 \pm 4.7$ & 0.100 \\
\hline $\mathrm{RDW}$, mean $\pm \mathrm{SD}$ & $14.7 \pm 1.7$ & $15.1 \pm 1.6$ & $14.6 \pm 1.8$ & 0.144 \\
\hline MPV, fL, mean $\pm S D$ & $8.5 \pm 1.0$ & $8.7 \pm 0.9$ & $8.5 \pm 1.1$ & 0.496 \\
\hline Total cholesterol, $\mathrm{mg} / \mathrm{dL}$, mean $\pm \mathrm{SD}$ & $168 \pm 42$ & $172 \pm 50$ & $166 \pm 39$ & 0.565 \\
\hline $\mathrm{HDL}, \mathrm{mg} / \mathrm{dL}$, mean $\pm \mathrm{SD}$ & $39 \pm 10$ & $39 \pm 10$ & $40 \pm 10$ & 0.718 \\
\hline LDL, mg/dL, mean $\pm S D$ & $97 \pm 34$ & $104 \pm 39$ & $95 \pm 32$ & 0.286 \\
\hline Triglycerides, mg/dL, median $\left(25^{\text {th }}-75^{\text {th }}\right.$ IQR $)$ & $136(102-195)$ & $123(95-189)$ & $136(104-204)$ & 0.526 \\
\hline Total protein, $\mathrm{g} / \mathrm{dL}$, mean $\pm \mathrm{SD}$ & $6.7 \pm 0.7$ & $6.7 \pm 0.8$ & $6.7 \pm 0.6$ & 0.960 \\
\hline Albumin, $\mathrm{g} / \mathrm{dL}$, mean $\pm \mathrm{SD}$ & $4.1 \pm 0.4$ & $4.1 \pm 0.5$ & $4.2 \pm 0.4$ & 0.503 \\
\hline
\end{tabular}


$\mathrm{CIN}$ also negatively influences the recovery of EF and survival in patients undergoing CRT implantation (20). Cardiorenal syndrome (CRS) type 3 is a subtype of the CRS. This type of CRS leads to acute kidney injury that aggravates and contributes to acute cardiac injury (21). This association can be explained by the close relationship between renal and cardiac function. As the reduction in cardiac output damages kidney functions, impaired kidney functions may also cause worsening in cardiac performance. Survival benefit in CRT responders is reduced if CIN occurs after the procedure (20).

MS has been developed to detect patients at risk of $\mathrm{CIN}$ in patients undergoing $\mathrm{PCl}$. Although persistent renal dysfunction requiring routine hemodialysis after $\mathrm{CIN}$ is extremely rare, up to $45.9 \%$ of patients with $\mathrm{CIN}$ may have permanent renal failure (22). This complication is also associated with higher mortality and morbidity (11).

There are some limitations of this study. Firstly, this is a single-center study with relatively small sample size. Second, it is a retrospective study, and the results need to be further

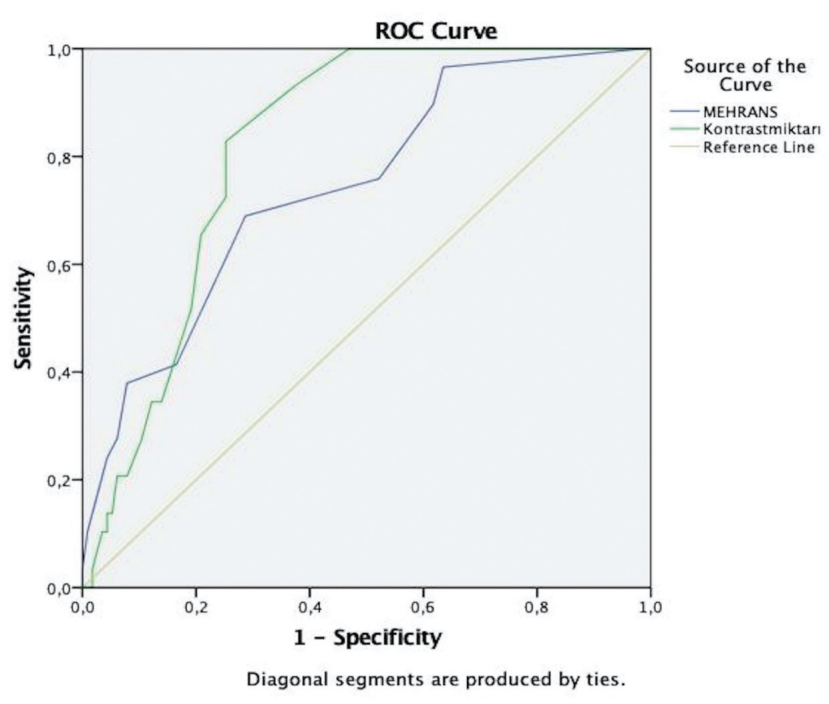

Figure 1. Mehran risk score cut-off value at admission for predicting contrast induced nephropathy based on receiver-operating characteristic curve analysis

ROC: Receiver-operating characteristic

\begin{tabular}{|c|c|c|c|c|}
\hline & Total $(n=144)$ & CIN $(+)(n=29)$ & CIN (-) (n=115) & p \\
\hline Left-bundle branch block & $139(96)$ & $28(97)$ & $111(96)$ & 0.994 \\
\hline Length of hospitalization, days, median $\left(25^{\text {th }}-75^{\text {th }}\right.$ IQR $)$ & $4(2-11)$ & $8(4.5-17.5)$ & $3(1-8)$ & 0.001 \\
\hline Contrast volume, $\mathrm{mL}$, mean $\pm \mathrm{SD}$ & $36 \pm 24$ & $55 \pm 24$ & $31 \pm 23$ & $<0.001$ \\
\hline LVEF, $\%$, mean \pm SD & $25 \pm 7$ & $22 \pm 6$ & $26 \pm 7$ & 0.005 \\
\hline \multicolumn{5}{|l|}{ NYHA, n (\%) } \\
\hline Class I-II & $112(78)$ & $18(62)$ & $94(82)$ & \multirow[t]{2}{*}{0.023} \\
\hline Class III-IV & $32(22)$ & $11(38)$ & $21(18)$ & \\
\hline Mehran risk score, mean $\pm \mathrm{SD}$ & $8.2 \pm 3.0$ & $10.4 \pm 3.3$ & $7.6 \pm 2.7$ & $<0.001$ \\
\hline
\end{tabular}

\begin{tabular}{|c|c|c|c|c|}
\hline \multirow[b]{2}{*}{ Variables } & \multicolumn{2}{|c|}{ Univariate analysis } & \multicolumn{2}{|c|}{ Multivariate analysis } \\
\hline & OR (95\% Cl) & $p$ & OR (95\% Cl) & $\mathbf{p}$ \\
\hline Age & $1.06(1.01-1.11)$ & 0.021 & $1.03(0.98-1.09)$ & 0.236 \\
\hline Gender & $1.80(0.74-4.35)$ & 0.191 & & \\
\hline Diabetes mellitus & $1.91(0.84-4.36)$ & 0.125 & & \\
\hline Hypertension & $0.62(0.27-1.43)$ & 0.264 & & \\
\hline Coronary artery disease & $1.71(0.72-4.07)$ & 0.226 & & \\
\hline Dyslipidemia & $1.21(0.53-2.74)$ & 0.649 & & \\
\hline Ischemic heart failure & $1.57(0.67-3.66)$ & 0.299 & & \\
\hline MRA & $0.77(0.30-1.93)$ & 0.573 & & \\
\hline RAAS blockers & $0.87(0.26-2.86)$ & 0.814 & & \\
\hline Contrast volume, $\mathrm{mL}$ & $1.03(1.02-1.05)$ & $<0.001$ & $1.02(1.00-1.04)$ & 0.029 \\
\hline Creatinine & $2.85(1.12-7.22)$ & 0.027 & $0.63(0.17-2.31)$ & 0.490 \\
\hline LVEF & $0.92(0.86-0.98)$ & 0.008 & $0.94(0.86-1.02)$ & 0.132 \\
\hline Mehran risk score & $1.35(1.17-1.56)$ & $<0.001$ & $1.34(1.10-1.63)$ & 0.004 \\
\hline
\end{tabular}




\begin{tabular}{|c|c|c|c|c|}
\hline & Cut off value & AUC & Sensitivity, \% & Specificity, \% \\
\hline Mehran risk score & 8.5 & $0.743(0.645-0.841)$ & 69 & 71 \\
\hline Contrast volume, $\mathrm{mL}$ & 43 & $0.819(0.751-0.886)$ & 65 & 80 \\
\hline
\end{tabular}

verified by prospective studies. Finally, the results are crosssectional, precluding the establishment of a causal relationship.

\section{Conclusion}

We found a higher MS as an independent risk factor for developing $\mathrm{CIN}$ in HF patients undergoing CRT implementation. A score of MS above 8.5 may warn the operators to take stricter preprocedural precautions and modify the potential risk factors for CIN after CRT implantation. Therefore, the data obtained from this study suggest that MS can be used in risk stratification for CIN following CRT implementation in individuals with advanced HF.

\section{Ethics}

Ethics Committee Approval: The study was approved by the Ankara City Hospital Institutional Ethics Committee (decision no: E2-20-57, date: 16.12.2020).

Informed Consent: Retrospective study.

Peer-review: Externally peer-reviewed.

\section{Authorship Contributions}

Concept: A.E., M.Ö., A.A., Design: M.A.E., M.Ö., M.K. Data Collection or Processing: M.E., K.D., A.A., Analysis or Interpretation: A.E., A.B.A., S.T., Literature Search: A.C.Ö., M.E., K.D., Ç.Y., Writing: M.A.E., M.K., A.B.A.

Conflict of Interest: No conflict of interest was declared by the authors.

Financial Disclosure: The authors declared that this study received no financial support.

\section{References}

1. Benjamin EJ, Virani SS, Callaway CW, et al. Heart Disease and Stroke Statistics-2018 Update: A Report From the American Heart Association. Circulation. 2018;137:67-492.

2. Ponikowski P, Voors AA, Anker SD, et al. 2016 ESC Guidelines for the diagnosis and treatment of acute and chronic heart failure: The Task Force for the diagnosis and treatment of acute and chronic heart failure of the European Society of Cardiology (ESC)Developed with the special contribution of the Heart Failure Association (HFA) of the ESC. Eur Heart J. 2016;37:2129-2200.

3. McAlister FA, Ezekowitz J, Hooton N, et al. Cardiac resynchronization therapy for patients with left ventricular systolic dysfunction: a systematic review. JAMA. 2007;297:2502-2514.
4. Boriani G, Diemberger I. Cardiac resynchronization therapy in the real world: need to focus on implant rates, patient selection, co-morbidities, type of devices, and complications. Eur Heart J. 2017;38:2129-2131.

5. Singh JP, Klein HU, Huang DT, et al. Left ventricular lead position and clinical outcome in the multicenter automatic defibrillator implantation trial-cardiac resynchronization therapy (MADIT-CRT) trial. Circulation. 2011;123:1159-1166.

6. Bradley DJ. Combining resynchronization and defibrillation therapies for heart failure. JAMA. 2003;289:2719-2721.

7. McCullough PA, Wolyn R, Rocher LL, Levin RN, O'Neill WW. Acute renal failure after coronary intervention: incidence, risk factors, and relationship to mortality. Am J Med. 1997;103:368375.

8. Rihal CS, Textor SC, Grill DE, et al. Incidence and prognostic importance of acute renal failure after percutaneous coronary intervention. Circulation. 2002;105:2259-2264.

9. Manske CL, Sprafka JM, Strony JT, Wang Y. Contrast nephropathy in azotemic diabetic patients undergoing coronary angiography. Am J Med. 1990;89:615-620

10. Cowburn PJ, Patel H, Pipes RR, Parker JD. Contrast nephropathy post cardiac resynchronization therapy: an under-recognized complication with important morbidity. Eur J Heart Fail. 2005;7:899-903.

11. Kowalczyk J, Lenarczyk R, Kowalski O, et al. Contrastinduced acute kidney injury in patients undergoing cardiac resynchronization therapy-incidence and prognostic importance. Sub-analysis of data from randomized TRUST CRT trial. J Interv Card Electrophysiol. 2014;40:1-8.

12. Mehran R, Aymong ED, Nikolsky E, et al. A simple risk score for prediction of contrast-induced nephropathy after percutaneous coronary intervention: development and initial validation. J Am Coll Cardiol. 2004;44:1393-1399.

13. Douglas PS, Carabello BA, Lang RM, et al. 2019 ACC/AHA/ ASE Key Data Elements and Definitions for Transthoracic Echocardiography: A Report of the American College of Cardiology/American Heart Association Task Force on Clinical Data Standards (Writing Committee to Develop Cardiovascular Endpoints Data Standards) and the American Society of Echocardiography. J Am Coll Cardiol. 2019;74:403-469.

14. Solomon R. Contrast-induced acute kidney injury (CIAKI). Radiol Clin North Am. 2009;47:783-788.

15. Khwaja A. KDIGO clinical practice guidelines for acute kidney injury. Nephron Clin Pract. 2012;120:179-184

16. Lameire N, Kellum JA; KDIGO AKI Guideline Work Group. Contrast-induced acute kidney injury and renal support for acute kidney injury: a KDIGO summary (Part 2). Crit Care. 2013;17:205. 
17. Liu ZZ, Schmerbach K, Lu Y, et al. lodinated contrast media cause direct tubular cell damage, leading to oxidative stress, low nitric oxide, and impairment of tubuloglomerular feedback. Am J Physiol Renal Physiol. 2014;306:864-872.

18. McCullough PA, Choi JP, Feghali GA, et al. Contrast-Induced Acute Kidney Injury. J Am Coll Cardiol. 2016;68:1465-1473.

19. Tester GA, Noheria A, Carrico HL, et al. Impact of radiocontrast use during left ventricular pacemaker lead implantation for cardiac resynchronization therapy. Europace. 2012;14:243248.
20. Strisciuglio T, Ammirati G, Pergola V, et al. Contrast-induced nephropathy after cardiac resynchronization therapy implant impairs the recovery of ejection fraction in responders. ESC Heart Fail. 2019;6:1266-1273.

21. Bagshaw SM, Hoste EA, Braam B, et al. Cardiorenal syndrome type 3: pathophysiologic and epidemiologic considerations. Contrib Nephrol. 2013;182:137-157.

22. Dangas G, lakovou I, Nikolsky E, et al. Contrast-induced nephropathy after percutaneous coronary interventions in relation to chronic kidney disease and hemodynamic variables. Am J Cardiol. 2005;95:13-19. 